\title{
Исследования издержек финансовой неустойчивости в рамках компромиссной теории структуры капитала: обзор
}

\author{
Семенова Е., ${ }^{39}$ Смирнова И. ${ }^{40}$
}

Проблема оптимизации структуры капитала фирмы является одной из центральных в теории корпоративных финансов, а также играет определяюшую роль при принятии решений по финансированию операщионной деятельности и инвестиционных проектов. Инициаторами исследований в данной области стали [Modigliani \& Miller,1958, 1963], которые в paбomax "The cost of capital, corporation finance and the theory of investment» $u$ "Corporation income taxes and the cost of capital: A correction» nопьтались оценить влияние налоговых выгод, получаемых от долгового финансирования, на принятие фирмами решений относительно структуры капитала. Названные работы Modigliani \& Miller, так же как и статьи, появившиеся позже [Baxter, 1967; Brennan \& Schwartz, 1978; Kraus \& Litzenberger, 1973; Scott, 1976], позволили сформировать общий взгляд на проблему определения оптимальной структурь капитала на основе его компромиссной теории (trade-off theory): оптимальная пропоричи собственного и заемного капитала должна уравновешивать выгоды долгового финансирования, возникающие ввиду наличия налогового щичта, $c$ издержками долгового финансирования, нарастающими по мере роста доли заемного капитала. Компромиссная конщепция предполагает, что налоговые выгоды, связанные с использованием долгового финансирования, являются одним из основных факторов, определяющих существование оптимальной структуры капитала: когда отношение долг/собственный капитал низкое, увеличение долга ведет к пропорииональному росту стоимости фирмы благодаря действию эффекта налогового щита. Дальнейшее увеличение доли долга в капитале приводит к росту издержек финансовой неустойчивости, что приводит $\kappa$ падению стоимости фирмы. Таким образом, при определенном соотномении долг/собственный капитал предельные издержки и выгоды, связанные с заемным финансированием, уравновешиваются, и именно в этот момент стоимость фирмы достигает максимума.

В последние годы появились интересные и достаточно разные исследования издержек, сопряженных с увеличением долга [Andrade \& Kaplan, 1998; Almeida \& Philippon, 2006; Philosophov\&Philosophov, 1999, 2002, 2005]. По мнению авторов, основнылм фактором, накладывающим ограничения на величину заимствований, является риск банкротства, в связи с чем центральным моментом данных работ является разработка и реализачия подхода к расчету вероятности банкротства.

Цель данного обзора - провести анализ академических публикаций, посвященных издержкам финансовой неустойчивости.

\footnotetext{
39 Магистр программы «Стратегическое управление финансами фирмы» факультета экономики ГУ ВШЭ.

40 Магистр программы «Стратегическое управление финансами фирмы» факультета экономики ГУ ВШЭ.
} 


\section{Исследования природы издержек финансовой неустойчивости}

Одна из первых работ, посвященных изучению природы издержек финансовой неустойчивости, появились в конце 1970-х годов. [Warner J., 1977] исследовал 11 железнодорожных компаний с целью оценки прямых издержек банкротства. Взяв величину издержек, связанных с процессом банкротства, из документов Международной торговой палаты (ICC) и сопоставив их с совокупной рыночной стоимостью (долг плюс капитал), которую демонстрировали фирмы за семь лет до того, как было возбуждено дело о банкротстве, Warner установил, что прямые издержки неустойчивости в среднем составляют $1 \%$, и возрастают до $5,3 \%$, если в качестве базы использовать стоимость фирм непосредственно перед банкротством. Он заключил, что ожидаемые прямые издержки финансовой неустойчивости столь незначительны, что их нельзя считать достаточными для оказания влияния на формирование цены долга и выбор структуры капитала: «Ожидаемые прямые издержки банкротства однозначно меньше налоговых выгод долга, которые ожидаются при данной налоговой ставке в стандартных моделях оценки» [8]. Данный вывод во многом обусловлен тем, что Warner не брал в рассмотрение косвенные издержки банкротства, что может приводить к значительному занижению оценок по сравнению с действительными суммами расходов, которые несут фирмы, находясь в состоянии неустойчивости.

Тему оценки прямых издержек продолжил [Weiss, 1990]. Несмотря на то, что Weiss в своей работе указывает и на наличие неявных издержек банкротства, выражающихся в различных альтернативных издержках (потеря рыночной доли и снижение стоимости запасов, рост операционных издержек, снижение конкурентоспособности фирмы), он не включает их в свой анализ, утверждая, что они не поддаются оценке. По расчетам Weiss на основе данных по компаниям из различных отраслей, прошедших через процедуру банкротства в период с ноября 1979-го по декабрь 1986 г., в зависимости от выбора меры оценки размеров фирмы издержки банкротства составили в среднем 20,6\% от рыночной стоимости собственного капитала (колеблясь от 2 до 63,3\%), или 3,1\% от суммы балансовой стоимости долга и рыночной стоимости собственного капитала (диапазон колебаний $1-6,6 \%)$. На основании своих расчетов, повторяя логику Warner, Weiss соглашается с ним в том, что прямые издержки банкротства не играют существенной роли при выборе фирмами структуры капитала и не влияют на устанавливаемую кредиторами цену долга.

Выводы, полученные Warner и Weiss, подверглись критике со стороны [Altman, 1982], который указывал на необходимость включения в анализ неявных издержек банкротства (потерянные прибыли, которых по ожиданиям фирма может лишиться ввиду высокой вероятности банкротства; а также вероятность банкротства). Своим исследованием Altman совершил определенный прорыв в теории и практике оценки издержек неустойчивости, впервые предложив вариант аппроксимации неявных издержек банкротства.

Однако, так как все компании в выборке Altman имели отрицательные прибыли, то невозможно определенно сказать, какие же именно издержки были оценены автором статьи - COFD (cost of financial distress) или COED (costs of economic distress). В связи с этим применение оцененных Altman издержек банкротства для определения оптимальной структуры капитала (что он и делает в своей работе) нельзя назвать до конца правильным, так как в данном случае должны учитываться только те издержки, которые были вызваны последствиями финансовых решений фирмы. 
На этот недостаток предложенного Altman принципа оценки издержек банкротства обращают внимание [Opler T.C. и Titman S., 1982] в своей статье «Financial Distress and Corporate Performance». Для того чтобы избежать проблем, связанных с выделением из общих издержек неустойчивости тех, которые могут быть отнесены именно к финансовой неустойчивости, Opler\&Titman меняют методологию проведения исследования. Они отобрали отрасли, которые испытывали негативные экономические шоки, и в этих отраслях проанализировали последствия шоков для фирм, которые характеризовались высоким финансовым рычагом, и фирм, которые более консервативно подходили к вопросу долгового финансирования. Своим исследованием Opler\&Titman тестировали следующую гипотезу: «если финансовая неустойчивость несет в себе издержки, то фирмы с большим рычагом должны нести более значительные операционные потери».

Выводы Opler\&Titman подтверждают выдвинутую ими гипотезу: фирмы, которые характеризовались высоким финансовым рычагом, теряли большую рыночную долю, чем их более консервативные конкуренты. Данный факт объясняется Opler\&Titman с трех позиций:

- $\quad$ с позиции покупателей: нежелание покупателей продолжать отношения с фирмой, испытывающей определенные трудности;

- $\quad c$ позиции конкурентов: финансово сильные компании могут воспользоваться своими преимуществами, проводя агрессивные рекламные кампании или изменяя политику ценообразования с целью вытеснения с рынка уязвимого конкурента;

- $\quad c$ позиции менеджмента: неспособность менеджмента компаний со слишком высоким долгом воспользоваться имеющимися инвестиционными возможностями.

Основной вывод работы Opler\&Titman можно сформулировать следующим образом: для компании обладание высоким финансовым рычагом является затратным. При этом авторы статьи не делают попыток проведения количественной оценки COFD. Другими словами, они не решают в полной мере проблему, которую сами обозначили, ссылаясь на работу Altman.

Проблема выделения исключительно издержек финансовой неустойчивости (COFD) была разрешена значительно позже [Andrade \& Kaplan,1998], которые показали, что COFD составляют от 10 до 23\% от первоначальной стоимости фирмы. Однако авторы были убеждены в том, что с точки зрения еx ante сопоставления ожидаемых COFD с налоговыми выгодами и стимулами долга, данные издержки финансовой неустойчивости должны быть относительно малыми, и соответственно будут оказывать незначительное влияние при выборе оптимальной структуры капитала.

[Almeida \& Philippon, 2006] указывают на ошибочность данного вывода, утверждая, что в действительности величина ex-ante издержек неустойчивости существенно недооценена ввиду игнорирования риска, а следовательно, ex-anteиздержки неустойчивости нельзя считать умеренными. Методология Almeida \& Philippon предполагает использование оценок ex-post-издержек финансовой неустойчивости, рассчитанных [Andrade \& Kaplan, 1998], а также включает применение наблюдаемых кредитных спрэдов (observed credit spreads) для вывода подразумеваемой рынком (market-implied), скорректированной на риск (или нейтральной к риску) вероятности банкротства. Полученные авторами скорректированные на риск вероятности банкротства, а следовательно, скорректированная на риск NPV издержек неустойчивости значительно превосходят по величине исторические вероятности банкротства и нескорректированную на риск NPV издержек финансовой неустойчивости. Предложенная Almeida \& Philippon методология позволяет объяснить полученные 
[Graham, 2000] выводы о консервативности фирм при определении суммы долга, так как в соответствии с этой методологией предельные скорректированные на риск издержки финансовой неустойчивости могут иметь то же значение, что и предельные налоговые выгоды долга, рассчитанные Graham.

Направление, открытое Almeida \& Philippon, было продолжено в статьях русских исследователей [Philosophov\&Philosophov, 1999, 2002, 2005], которые представили новый вероятностный подход к проблеме оптимизации структуры капитала компании. По мнению авторов, основным фактором, накладывающим ограничения на величину заимствований, является риск банкротства, в связи с чемцелью представленных работ является расчет вероятности банкротства для различных временных горизонтов и для различных долей долгового капитала, а также оценка влияния рассчитанных вероятностей на стоимость компании. Проблема прогноза вероятности банкротства рассматривается с использованием многовариантного подхода теории статистических решений, который предполагает совместное использование финансовой информации о фирмах, различающихся временем, оставшимся до банкротства. Преимущество многовариантного подхода, с точки зрения его авторов, заключается в том, что он (в силу отсутствия чрезмерно формализованных моделей) может использоваться при принятии практических решений относительно структуры капитала.

Согласно исследованию авторов, склонность фирмы к банкротству определяется не величиной совокупного долга, а величиной текущих обязательств, которые, как правило, радикально увеличиваются в год, предшествующий банкротству. В большинстве случаев банкротство происходит по причине достижения сроков погашения крупной части долгосрочного долга, который трансформируется в текущие обязательства в последний год перед погашением. Иногда такой перевод долгосрочного долга в текущие обязательства становится непосредственной причиной банкротства. В то же время долгосрочный долг может даже уменьшиться в последний год перед банкротством. Таким образом, оптимальное соотношение собственного и заемного капитала зависит от структуры заемного капитала, то есть от доли долгосрочных и краткосрочных обязательств и от сроков погашения долгосрочного долга.

Altman в своей работе «A Further Investigation of the Bankruptcy Cost Question» (1984) опирается на подход, предложенный [Morris, 1982] [2], который попытался определить условия, при которых оптимальная структура капитала могла бы существовать. Morris представил модель, опирающуюся на предельные ожидаемые издержки банкротства, которые, по его убеждению, усиливают доводы в пользу существования оптимальной структуры капитала, но не являются абсолютно необходимыми. Подход Morris заключается в разработке выражения для приведенной стоимости ожидаемых налоговых выгод и издержек банкротства и анализе условия первого порядка.

Altman в первую очередь пытался установить, действительно ли ожидаемая текущая стоимость издержек банкротства превосходит ожидаемую приведенную стоимость налоговых выгод от рычага. Если издержки банкротства выше налоговых выгод, то можно заключить, что фирма имеет излишний рычаг в своей структуре капитала и оптимальная точка, по крайней мере в соответствии с соотношением издержки банкротства/налоговые выгоды, находится при меньшем отношении долг/собственный капитал.

Altman исследует соотношение между ожидаемыми издержками дефолта и ожидаемыми налоговыми выгодами от выплаты процентов по долговым ценным бумагам. Данное сопоставление в аналитическом виде может быть представлено как: 


$$
\frac{P_{B, t}\left(B C D_{t}+B C I_{t}\right) \cdot(P V)_{t}}{M V_{t}} v s . \frac{T_{c}(i D)_{t}(P V)_{t} \cdot\left(1-P_{B, t}\right)}{M V_{t}},
$$

где $P_{B, t}$ - вероятность банкротства фирмы в момент времени $t$;

$B C D_{t}$ - явные издержки банкротства в момент времени $t$;

$B C I_{t}$ - неявные издержки банкротства в момент времени $t$;

$M V_{t}$ - рыночная стоимость фирмы в момент времени $t$;

$T_{c}$ - предельная ставка налога на прибыль корпораций;

$i D$ - процентные расходы начиная с периода $t$ до бесконечности;

$(P V)_{t}$ - стоимость фирмы, приведенная к моменту времени $t$.

Нетривиальной задачей при проведении сравнительного анализа по формуле (1) является оценки сопряженных с привлечением долга потерь, которые могут быть как прямыми, так и косвенными. Altman представляет простую модель идентификации и измерения ожидаемых издержек банкротства и для американских фирм проводит анализ трех аспектов: явные издержки банкротства, включающие судебные, аудиторские, регистрационные и прочие административные расходы; неявные издержки банкротства, а именно потерянные прибыли, которых по ожиданиям фирма может лишиться ввиду высокой вероятности банкротства; а также вероятность банкротства. Данные элементы рассматриваются совместно с целью определения ожидаемой приведенной стоимости издержек банкротства, которые затем сопоставляются с ожидаемой приведенной стоимостью налоговых выгод от финансового рычага.

Значимость вклада Altman состоит в том, что он акцентирует внимание на неявных издержках банкротства, которые до сих пор лишь назывались теоретиками, но при этом не делалось попыток их количественной оценки. Наряду с явными издержками банкротства, обсуждаемыми ранее, такими как регистрационные платежи, арбитражные расходы, судебные и аудиторские расходы и прочие издержки реорганизации или ликвидации, Altman выделяет альтернативные издержки упущенной управленческой энергии (opportunity costs of lost managerial energies), упущенные продажи, упущенные прибыли, более высокие затраты на заемный капитал, а также неспособность фирмы привлечь дополнительный капитал в виде нового долга или выпуска акций для финансирования инвестиционных возможностей, относя их к числу неявных издержек банкротства.

Поскольку неявные издержки банкротства не являются непосредственно наблюдаемыми, Altman предлагает свой вариант proxy для BCI (косвенные издержки финансовой неустойчивости), основывающийся на концепции прогнозных продаж и прибылей. Неявные издержки банкротства выражаются в виде неожидаемой прибыли (потерь) (abnormal profits (losses)), равной спрэду между ожидаемыми и фактическими прибылями. Для оценки ожидаемых прибылей он разрабатывает две модели: в основе первой лежит регрессионный анализ (построенние регрессии выручки компании на соответствующую величину продаж отрасли в целом), в основе второй модели лежат мнения экспертов относительно будущих прибылей компании.

Оценив неявные и явные издержки банкротства, Altman сопоставил их с общей стоимостью фирмы, определяемой как сумма рыночной стоимости собственного капитала (привилегированные и обыкновенные акции), рыночной стоимости долга, балансовой стоимости прочих долговых обязательств и капитализированной стоимости финансового лизинга. Средний процент совокупных издержек банкротства по отношению к стоимости фирмы, полученный 
Altman, был равен 8,7\% в момент времени $t$-3 и $12,2 \%$ в момент времени $t$ (в год банкротства, определяемого как дата возбуждения дела о банкротстве) для розничных компаний. Что касается промышленных компаний, то полученные результаты оказались значительно выше - 23,7\% в среднем в периоде $t$ и $17,4 \%$ в периоде $t$-3. Для объединенной выборки величина совокупных издержек банкротства по сравнению со стоимостью фирмы непосредственно перед банкротством в среднем равнялась $16,7 \%$.

Исходя из полученных результатов, Altman утверждает, что издержки банкротства не могут быть просто проигнорированы как незначительно отличающиеся от 0. Altman первым обращает внимание на то, что в действительности данные издержки являются достаточно крупными, чтобы при рассмотрении их в совокупности с вероятностью банкротства и в терминах приведенной стоимости результат оставался существенным для определения политики выбора структуры капитала.

Важным моментом при сопоставлении издержек и выгод долга является вероятность банкротства, которой в последующем уделялось много внимания [Philosophov \& Philosophov,2002, 2005; Almeida \& Philippon, 2006]. В своей работе Altman для определения вероятности банкротства фирмы в любой момент времени воспользовался моделью Z-счетов. Также Altman подчеркивает то, что налоговые выгоды должны корректироваться на вероятность того, что фирма не обанкротиться $\left(1-P_{B, t}\right)$, поскольку фирма может получать выгоды от наличия долга, только если она продолжает оставаться действующим предприятием. В случае ликвидации эти выгоды теряются полностью. Ставка процента, уровень долга и предельная ставка налога, по предположению Altman, остаются неизменными в течение бесконечного периода времени. Также Altman использовал две схемы определения ожидаемой приведенной стоимости налоговых выгод, которые рассчитывались либо только на основе процентного долга, либо на основе процентного долга и капитализированного лизинга.

Для простоты расчета соотношение издержки/выгоды было определено в терминах абсолютных величин — вместо предельного анализа. Однако стоит отметить, что предельное увеличение приведенной стоимости издержек банкротства может превысить предельные налоговые выгоды от процентных платежей до того, как абсолютное соотношение перестанет стимулировать дальнейшее увеличение рычага. Так может произойти по причине того, что вероятность банкротства повышается с возрастающим темпом, как только долг превысит определенную величину, в то время как ожидаемые налоговые выгоды линейны или, возможно, являются убывающей функцией от вероятности банкротства.

Результаты оценки, проведенной Altman, свидетельствуют о том, что большинство фирм имели излишний уровень долга в структуре капитала за год до объявления банкротства: 12 из 14 фирм, если налоговые выгоды рассчитывались только по процентному долгу, и 10 из 14, если также учитывался капитализированный лизинг. Хотя существуют другие факторы помимо агрегированного размера рычага и ex-ante-факторов банкротства, таких как недостаток денежных средств для покрытия текущих обязательств, утверждение относительно излишнего уровня долга в структуре капитала является наиболее релевантным для соотношения издержки банкротства vs. налоговые выгоды.

Своей работой Altman совершил определенный прорыв в теории и практике оценки издержек неустойчивости, впервые предложив вариант аппроксимации неявных издержек банкротства. Однако полученные Altman результаты не могут использоваться в качестве возможной оценки издержек исключительно финансовой неустойчивости, поскольку он не проводит водораздела между тем, 
какого рода неустойчивость была испытана компаниями - финансовая или экономическая. Так как все компании в выборке Altman имели отрицательные прибыли, то невозможно определенно сказать, какие же именно издержки были оценены автором статьи - COFD или COED (costs of economic distress). В связи с этим, применение оцененных Altman издержек банкротства для определения оптимальной структуры капитала (что он и делает в своей работе) нельзя назвать до конца правильным, так как в данном случае должны учитываться только те издержки, которые были вызваны последствиями финансовых решений фирмы. Кроме того, результаты, полученные Altman, фактически не решают загадки компромиссной теории. В ходе своего анализа Altman установил, что фирмы, находящиеся на грани банкротства, имели излишний финансовый рычаг, но действительно ли ожидаемые издержки банкротства будут достаточно велики при нормальных условиях и каков должен быть рычаг в этом случае согласно соотношению издержки/выгоды долга, Altman не определял.

Более точную оценку издержек долга, вызванных именно финансовой неустойчивостью, попытались дать [G. Andrade и S.N. Kaplan, 1998] в работе «Ноw costly is financial (not economic) distress? Evidence from highly leveraged». Andrade \& Kaplan поставили перед собой проблему оценки прямых и косвенных издержек финансовой неустойчивости, а также постарались выявить, какие именно факторы определяют эти издержки. По мнению авторов, сложность вычисления величины COFD заключается в неспособности некоторых авторов [2, 5] четко установить причинно-следственные связи: «Низкие показатели деятельности (poor performance) компании, находящейся в состоянии финансовой неустойчивости, вызваны именно положением компании, или же на первом месте стоят факторы, которые изначально привели компанию к финансовой неустойчивости» [3].

Чтобы избежать прошлых ошибок, Andrade \& Kaplan постарались отделить финансово неустойчивые фирмы от экономически неустойчивых, то есть определить издержки «чистой» финансовой неустойчивости. Для этого они в своем исследовании использовали данные по 31 сделке с долговым финансированием (highly leveraged transactions, HLTs) 1980-х годов, которые впоследствии привели фирмы в состояние финансовой неустойчивости. При этом в момент неустойчивости у всех фирм из выборки сохранялась положительная операционная маржа, которая в большинстве случаев превышала среднеотраслевую. Более того, проведя анализ чувствительности, Andrade \& Kaplan установили, что высокий рычаг является первопричиной финансовой неустойчивости, тогда как низкие показатели деятельности фирмы (poor firm performance), низкий уровень функционирования отрасли (роor industry performance) или краткосрочные изменения процентных ставок играют куда меньшую роль в предопределении финансовой неустойчивости.

Для того чтобы дать количественную оценку COFD, Andrade \& Kaplan сопоставляли операционные показатели, а также стоимость фирмы (сумма рыночных стоимостей долга и собственного капитала) в момент, когда фирма объявлялась финансово неустойчивой, со значениями этих показателей после преодоления состояния финансовой неустойчивости. Для этих целей Andrade \& Kaplan использовали два определения состояния финансовой неустойчивости: a) неспособность осуществить очередные выплаты по долгу (Interest/EBIT <1); b) попытки фирмы реструктуризировать свой долг по причине сложности выполнения очередных выплат.

В результате оценки процентных изменений операционных показателей деятельности фирмы (operating performance) Andrade \& Kaplan пришли к выводу, что снижение операционной маржи (EBITDA/sales) и маржи чистых денежных потоков ([EBITDA - capital expenditure $] /$ sales $)$ в среднем приводит к чистым 
COFD в размере $10-15 \%$ от стоимости фирмы до наступления состояния финансовой неустойчивости. Однако данное заключение требует выполнения двух важных предпосылок: 1) типичная фирма не испытывала неблагоприятного влияния экономический шоков или экономической неустойчивости; 2) момент вступления фирмы в состояние финансовой неустойчивости точно определен (год, когда коэффициент процентного покрытия становится меньше 1).

Более полную оценку величины чистых издержек финансовой неустойчивости Andrade \& Kaplan получили в результате анализа изменения рыночной стоимости фирмы до и после финансовой неустойчивости. В то время как [Weiss, 1990] оценил прямые издержки финансовой неустойчивости на уровне $3,1 \%$ от стоимости фирмы, анализ Andrade \& Kaplan показал, что COFD составляют от 10 до 23\% от первоначальной стоимости фирмы. При этом авторы убеждены в том, что с точки зрения ех-ante-сопоставления ожидаемых COFD c налоговыми выгодами и стимулами долга данные издержки финансовой неустойчивости должны быть относительно малыми. В то же время непосредственного сопоставления ех-ante-издержек финансовой неустойчивости с ожидаемыми выгодами от повышения финансового рычага Andrade \& Kaplan не проводили.

\section{Исследования вероятности банкротства}

Для оценки вероятности банкротства, которая во многом определяет значимость приведенных ожидаемых издержек финансовой неустойчивости, Altman использовал свою модель Z-счетов. В последующих работах вопрос определения вероятности банкротства и ее влияния на установление оптимальной структуры капитала подлежал детальному рассмотрению. В частности, Almeida \& Philippon строят свой анализ на оценке вероятности возникновения финансовой неустойчивости, скорректированной на риск, и опровергают мнение о том, что даже если ex-post-потери составляют величину в $10-20 \%$ от стоимости фирмы, exante-издержки неустойчивости являются умеренными, поскольку вероятность финансовой неустойчивости очень мала для большинства открытых компаний [3, 6]. Almeida \& Philippon показывают, что в действительности величина ex-anteиздержек неустойчивости существенно недооценена ввиду игнорирования риска, а следовательно, ex-ante-издержки неустойчивости нельзя считать умеренными.

В своей статье Almeida \& Philippon предлагают новый подход к оценке NPVиздержек финансовой неустойчивости, критикуя применявшиеся ранее методы оценки ех-ante-издержек финансовой неустойчивости за то, что они либо игнорируют капитализацию и принцип дисконтирования [6, 7], либо предполагают нейтральность к риску и дисконтируют результаты исторических вероятностей и потерь в стоимости при банкротстве по безрисковой ставке [2]. Методология Almeida \& Philippon предполагает использование оценок ex-post-издержек финансовой неустойчивости, рассчитанных [Andrade \& Kaplan, 1998], а также включает применение наблюдаемых кредитных спрэдов (observed credit spreads) для вывода подразумеваемой рынком (market-implied), скорректированной на риск (или нейтральной к риску) вероятности банкротства.

Полученные авторами скорректированные на риск вероятности банкротства, а следовательно, скорректированная на риск NPVиздержек неустойчивости значительно превосходят по величине исторические вероятности банкротства и нескорректированную на риск NPVиздержек финансовой неустойчивости. Предложенная Almeida \& Philippon методология позволяет объяснить полученные 
[Graham, 2000] выводы о консервативности фирм при определении суммы долга, так как в соответствии с этой методологией предельные скорректированные на риск издержки финансовой неустойчивости могут иметь то же значение, что и предельные налоговые выгоды долга, рассчитанные Graham.

\section{Налоговые выгоды долга}

C технической точки зрения, реализация подхода Graham к определению величины налоговых выгод от процентных вычетов предполагает оценку текущих процентных платежей и предельной ставки налога и не представляет особой сложности. Основными препятствиями могут стать доступность финансовой отчетности за необходимый промежуток времени, а также особенности учетной политики российских компаний. Под особенностями учетной политики понимается возникновение ситуации, когда в соответствии с отчетом о прибылях и убытках фирма имеет положительную прибыль, но налоги при этом не платятся ввиду различных причин (отложенные налоги, накопленные убытки). В этом случае фирма фактически не может воспользоваться преимуществами долгового финансирования, поскольку для этого она должна платить налоги.

Уроки для построения исследований финансовой неустойчивости в российской практике

Как было отмечено [Weiss, 1990], издержки неустойчивости делятся на явные и неявные, причем последние представляют наибольшую сложность с точки зрения оценки. Эмпирические исследования [Altman, 1984] и [Andrade \& Kaplan, 1998] проводились в условиях, отличных от тех, которыми характеризуются развивающиеся рынки капитала, следовательно, полученные ими оценки неправомерно использовать для определения величины издержек финансовой неустойчивости для российских компаний. Более того, при обращении к России возникают дополнительные сложности помимо идентификации и поиска способа аппроксимации неявных издержек финансовой неустойчивости:

- Очевидной проблемой является недостаточность исторических данных, на основе которых могут быть произведены расчеты для выведения исторических средних. Институт банкротства возник в России лишь в 1992 году, соответственно для проведения исследований доступны лишь 15 лет, около половины из которых приходится на период переходной экономики и могут приводить к «шуму»в выборке.

- Сложность представляет также определение момента банкротства фирмы. Altman под моментом банкротства понимал дату возбуждения дела о банкротстве. Andrade \& Kaplan применили два подхода к определению момента возникновения неустойчивости: а) неспособность осуществить очередные выплаты по долгу (Interest/EBIT <1); б) попытки фирмы реструктуризировать свой долг по причине сложности выполнения очередных выплат. Реализация подхода Altman в российских условиях может быть ограничена тем, что диапазоны коэффициентов, оговариваемые в законе о банкротстве, спорны и возможны ситуации, когда фирмы, которые по закону должны быть признаны банкротами, в действительности такими не являются. Следовательно, если опираться на данное Altman определение, то может возникнуть искаженное представление о доле обанкротившихся фирм. Применение подходов Andrade \& Kaplan может быть затруднено недоступностью информации, что особенно относится к 90-м годам.

- Существенной проблемой может стать выделение из рассчитанных издержек банкротства издержек, вызванных именно финансовой неустойчивости, возможность реализации подходов [Opler \& Titman, 1994] и Andrade \& Kaplan вызывает сомнения. 
Выводы Almeida \& Philippon показывают критичность верной оценки вероятности банкротства. Для проведения подобных исследований на российских данных может стать непреодолимой проблемой отсутствие релевантной информации:

- Оценка вероятности банкротства по рейтингам фактически невозможна, поскольку международными агентствами (Standard \& Poors, Moody's), которые позволяют оценить вероятность банкротства, рейтинг присвоен очень ограниченному числу российских компаний . Рейтинги, выстраиваемые российскими организациями (НИКойл), не ведут статистики по банкротству и соответственно нет возможности определить, с какой вероятностью данная фирма может оказаться в состоянии неустойчивости, обладая тем или иным рейтингом. В любом случае применение международных или синтетических рейтингов будет давать искаженную оценку исторической вероятности, так как эти оценки были получены при иных институциональных условиях.

- Реализация модели Z-счетов Altman, хотя она сегодня широко применяется банками при оценке кредитоспособности фирм, также вызывает сомнения. Однако, выбранные Altman характеризующие показатели, рассчитанные значения весовых коэффициентов и пороговых значений опираются на американские аналитические данные шестидесятых и семидесятых годов, то есть не могут соответствовать современной специфике экономической ситуации, в частности российской действительности. Построение аналогичной модели по российским данным затруднено, как уже было сказано выше, ограниченностью релевантной информации и длиной временного интервала.

- Оценка вероятностей, скорректированных на риск, как это предполагали Almeida \& Philippon, сопряжена с еще большим количеством проблем, нежели модель Z-счетов. Определение каждого из параметров требует проведения дополнительных исследований. В частности, необходимо установление исторического коэффициента покрытия, $\rho$. Нетривиальной задачей является выделение премии за риск банкротства в спрэде доходностей: проблему представляет определение самих спрэдов - что брать за безрисковую ставку, как оценивать доходность к погашению по долгу фирм. Для вычисления премии за риск банкротства необходимо оценить величину премии за ликвидность и налоговой премии, которые в работе Almeida \& Philippon рассчитывались как спрэд доходностей однолетней облигации с рейтингом ААА. Однако в России на сегодняшний день нет ни одной облигации, которая бы имела рейтинг ААА. Также чтобы рассчитать NPV издержек финансовой неустойчивости требуется безрисковая облигация, которая по своим параметрам соответствует облигации фирмы с определенным рейтингом.

Спорные моменты в процессе определения оптимального соотношения долг/собственный капитал для российских фирм также возникают в отношении налоговых выгод и особенно издержек финансовой неустойчивости,

С технической точки зрения, реализация подхода Graham к определению величины налоговых выгод от процентных вычетов, которая предполагает оценку текущих процентных платежей и предельной ставки налога, не представляет особой сложности. Основными препятствиями могут стать доступность финансовой отчетности за необходимый промежуток времени, а также особенности учетной политики российских компаний. Под особенностями учетной политики понимается возникновение ситуации, когда в соответствии с отчетом о прибылях и убытках фирма имеет положительную прибыль, но налоги при этом не платятся ввиду различных причин (отложенные налоги, накопленные убытки). В этом случае фирма фактически не может воспользоваться преимуществами долгового финансирования, поскольку для этого она должна платить налоги. 
Как было отмечено Weiss, неявные, причем последние представляют наибольшую сложность с точки зрения оценки. Эмпирические исследования Altman и Andrade \& Kaplan проводились в условиях, отличных от тех, которыми характеризуются развивающиеся рынки капитала, следовательно, полученные ими оценки неправомерно использовать для определения величины издержек финансового рычага для российских компаний. Более того, при обращении к России возникают дополнительные сложности помимо идентификации и поиска способа аппроксимации неявных издержек финансовой неустойчивости:

- Очевидной проблемой является недостаточность исторических данных, на основе которых могут быть произведены расчеты для выведения исторических средних. Институт банкротства возник в России лишь в 1992 году, соответственно для проведения исследований доступны лишь 15 лет, около половины из которых приходится на период переходной экономики и может приводить к «шуму»в выборке.

- Сложность представляет также определение момента банкротства фирмы. Altman под моментом банкротства понимал дату возбуждения дела о банкротстве. Andrade \& Kaplan применили два подхода к определению момента возникновения неустойчивости: а) неспособность осуществить очередные выплаты по долгу (Interest/EBIT <1); б) попытки фирмы реструктуризировать свой долг по причине сложности выполнения очередных выплат. Реализация подхода Altman в российских условиях может быть ограничена тем, что диапазоны коэффициентов, оговариваемые в законе о банкротстве, спорны и возможны ситуации, когда фирмы, которые по закону должны быть признаны банкротами, в действительности такими не являются. Следовательно, если опираться на данное Altman определение, то может возникнуть искаженное представление о доле обанкротившихся фирм. Применение подходов Andrade \& Kaplan может быть затруднено недоступностью информации, что особенно относится к 90-м годам.

- Существенной проблемой может стать выделение из рассчитанных издержек банкротства издержек, вызванных именно финансовой неустойчивостью, возможность реализации подходов Opler \& Titman и Andrade \& Kaplan вызывает сомнения.

\section{Список литературы}

1. Almeida H., Philippon T. The Risk-Adjusted Cost of Financial Distress Graft. 2006, pp.1-44.

2. Altman E. A Further Empirical Investigation of the Bankruptcy Cost Question / Journal of Finance. 1984, № 39, pp. 1067-1089.

3. Andrade G., Kaplan S. How Costly is Financial (not Economic) Distress? Evidence from Highly Leveraged Transactions that Become Distressed / Journal of Finance, 1998, № 53, pp. 1443-1493.

4. Graham J. How Big Are the Tax Benefits of Debt? / Journal of Finance, 2000, № 55, pp. 1901-1942.

5. Opler T.C., Titman S. Financial Distress and Corporate Performance / Journal of Finance, 1994, № 3, pp. 1015-1040.

6. Warner J. Bankruptcy Costs: Some Evidence / Journal of Finance, 1977, № 32, pp. 337-347.

7. Weiss L. Bankruptcy Resolution. Direct Costs and Violation of Priority of Claims / Journal of Financial Economics, 1990, № 27, pp. 255-311. 
8. Philosophov Leonid V., Philosophov Vladimir L. Corporate bankruptcy prognosis: An attempt at a combined prediction of the bankruptcy event and time interval of its occurrence. 2002.

9. Philosophov Leonid V., Philosophov Vladimir L. Optimization of a firm's capital structure: A quantitative approach based on a probabilistic prognosis of risk and time of bankruptcy. 2005. 